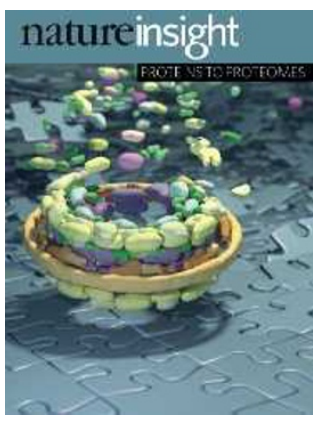

Cover illustration

The molecular architecture of the nuclear pore complex. (Courtesy of S. Parker and C. Silva, Scientific Computing and Imaging Institute, and R. K. Morley, RayScale).

\section{Editor, Nature}

Philip Campbell

Insights Publisher

Sarah Greaves

Publishing Assistant

Claudia Banks

Insights Editor

Ritu Dhand

\section{Production Editor}

Davina Dadley-Moore

Senior Art Editor

Martin Harrison

Art Editor

Nik Spencer

Sponsorship

Emma Green

Production

Jocelyn Hilton

\section{Marketing}

Katy Dunningham Elena Woodstock

Editorial Assistant Alison McGill

\title{
PROTEINS TO PROTEOMES
}

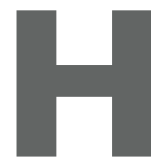
ow are innumerable protein functions integrated so that a living cell interacts coherently with its environment? This question is central to an emerging science of biological information processing systems biology.

For nearly two centuries, 'physiological chemists' had to tackle the opposite problem: making sense of the murky 'protoplasm' of cells by dividing it into separate components. From the discovery in 1840 of haemoglobin crystals in earthworm blood spread on glass plates, to the development of the ultracentrifuge in the 1920s, to contemporary genomics research, biochemists have strived to study life's parts in isolation. Now that part lists are almost complete, the pieces must be brought back together.

High-throughput proteomics has enabled large protein-interaction networks to be drafted, and the statistical analysis of these forms a busy branch of systems biology. But rather than just a 'dot' connected in a network, each protein is a complex and dynamic three-dimensional object with sophisticated chemical properties. And proteins can assemble into large, asymmetrical or transient molecular machines. Accurate descriptions of these assemblies, in turn, must reflect the cellular context in which they usually operate, a factor that also conditioned their evolution.

Cutting-edge protein science therefore remains central to any meaningful modelling of biological systems. This Insight covers some of the most vibrant areas of research into the 'protein world', taking a journey from single protein dynamics to functional proteomics and drug discovery, through some of the latest technological developments in structural, cellular, evolutionary and computational biology.

We are pleased to acknowledge the financial support of Pfizer in producing this Insight. As always, Nature carries sole responsibility for all editorial content and peer review.

Tanguy Chouard and Joshua Finkelstein, Senior Editors

\section{REVIEWS}

964 Dynamic personalities of proteins

K. Henzler-Wildman \& D. Kern

973 The molecular sociology of the cell

C. V. Robinson, A. Sali \&

W. Baumeister

983 The origin of protein interactions and allostery in colocalization

J. Kuriyan \& D. Eisenberg

991 The biological impact of mass-spectrometry-based proteomics

B. F. Cravatt, G. M. Simon \& J. R. Yates III

1001 Reaching for high-hanging fruit in drug discovery at protein-protein interfaces J. A. Wells \& C. L. McClendon

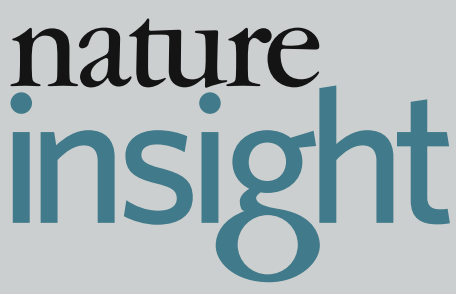

